\title{
Bacterial Surface Layer Proteins: A Promising Nano-Technological Tool for Bio-Sensing Applications
}

\author{
Anjali Sharma, Barkha Singhal* (i) \\ School of Biotechnology, Gautam Buddha University, Greater Noida (U.P.), India \\ Email: anjali220297@gmail.com, ^barkha@gbu.ac.in, ^gupta.barkha@gmail.com
}

How to cite this paper: Sharma, A. and Singhal, B. (2019) Bacterial Surface Layer Proteins: A Promising Nano-Technological Tool for Bio-Sensing Applications. Advances in Bioscience and Biotechnology, $10,42-58$

https://doi.org/10.4236/abb.2019.103004

Received: January 22, 2019

Accepted: March 23, 2019

Published: March 26, 2019

Copyright $\odot 2019$ by author(s) and Scientific Research Publishing Inc. This work is licensed under the Creative Commons Attribution International License (CC BY 4.0).

http://creativecommons.org/licenses/by/4.0/

\begin{abstract}
The phenomenal rise in the demand of biosensors accelerated their rapid development and immersive applications in the myriads of fields. The essential requirement of developing efficient bio-sensing platform is to find stable well organized interfacial architecture that can serve as an excellent matrix for binding and recognizing biomolecules. In this context, the enormous potential has been envisaged in surface layer proteins that represented themselves as most primitive and simplest self-assembled system with repetitive physicochemical properties for the molecular functionalization of surfaces and various interfaces. The prominence of S-layer proteins has been broadened by integrating genetic engineering approaches for the fine tuning of functional groups and protein domains in geometrically well-defined manner. The efficient and stable binding of various nanomaterials with S-layers in regular arrays has led to paradigmatic shift in their nano-biotechnological sensing applications. More recently, functional S-layer supported lipid membranes have been generated through covalent binding of lipid molecules either with native or recombinant S-layer proteins at nano-scale dimensions serving as "proof of concept" for the development of bio-sensing platform. Thus, in the light of benefits conferred by surface layer proteins for the development of highly efficient biosensors, an exciting path has been opened for broadening their translational applications in drug delivery, disease diagnosis, vaccines development, lab-on-chip devices etc. Therefore, this review intends to describe about the importance of surface layer proteins in the development of biosensors.
\end{abstract}

\section{Keywords}

Surface Layer Proteins, Nano-Patterning, Self-Assembly, Liposome, Biosensors 


\section{Introduction}

The past decade has seen expanding repertoire of bio-sensing devices that have been explicitly utilized in the field of biomedicine, diagnostics, food processing and safety, forensic sciences, security and environmental monitoring [1] [2] [3]. More recently, the advent of metabolic engineering and synthetic biology has paved the way for extensive development of in vivo biosensors that are based on biomolecular architecture comprising either proteins or nucleic acids [4]. These biosensors can be developed by the engineering of existing components for novel functions through rational design approaches and directed evolution, or directly obtained from genome mining. In spite of these marvelous credentials the field is impeded by pertaining to access the remote areas and complexity of the biological systems. The rapid technological intervention of nanotechnology and increasing impact in every facet of life offer bright prospects for the development of nanoscale bio-sensing devices that possess exquisite selectivity and sensitivity [5]. The fabrication of sensing devices at nanoscale dimension requires molecules possessing the capability of interlocking or self-assembling in predictable well-defined manner on various surfaces and interfaces. Therefore, there is burgeoning quest for molecular self-assembling systems that provides a better way of molecular-level manufacturing and precision for biological systems.

In this context, the importance of prokaryotic crystalline cell surface layer (S-layer) proteins has been increasingly realized by knowing the fact that these proteins represented themselves a unique self-assembling system utilized as patterning element for a bio-molecular recognition and quantification [6] [7]. The most remarkable property of native or genetically modified S-layer proteins is their ability to self-assemble in protein lattices on various artificial surfaces (e.g. noble metals, silicon surfaces, plastics) [8] or in suspension or on monolayer or bilayer Langmuir lipid films [9] [10] and liposomes [11] [12], and more recently emulsomes [13] [14]. The various functional groups (e.g. amino, carboxyl and hydroxyl groups) of native S-layer proteins or genetically modified functional domains confer repeated periodicity which resembles the lattice constants, leading to the formation of regular arrays on bound nanomaterials. Therefore, it's imperative to exploit S-layer proteins as a dispensable component for enhancing the sensitivity and stability of biosensors. However, significant attention has been drawn and challenges have been facing by scientific community for interfacing various biomolecules with a variety of nanomaterials that dictate the performance and sensitivity of biosensor. At present, the surface layer proteins of Gram positive bacteria have been explored for the development of various biosensors based on different transducers [15]. The current review describes the recent advancements, current bottlenecks and future prospects of biosensors based on surface layer proteins.

\section{Basic Architecture of Biosensors}

Biosensors are the devices used for the detection of biological analyte though the 
integration of biological recognition element having direct spatial contact with various transducing platforms that is capable of giving quantitative or semi-quantitative specific analytical information. Therefore, biosensors comprises of biological or biological derived molecules like enzymes, antibodies, nucleic acid, cell receptors, whole and immobilized microorganisms, tissues and organelles etc. with a physicochemical transducer elements that may be electrochemical [16], optical, magnetic, calorimetric, piezoelectric or acoustic transducers. The representative diagram depicting the basic components of biosensor are described in Figure 1. The working of biosensor is based on the recognition of biological samples with various bio-receptors including whole cells, immobilized cells and enzymes, antibody, nucleic acids, antigens etc. The recognition of samples has been followed by the conversion of the product that can be assessed and quantified by the suitable transducer that is based on the various physico-chemical properties of biological cells. An overview of the working of biosensor is presented in Figure 2.

The functionality of biosensors is highly dependent on stability and reproducibility of interfacial structure lies between bio-recognition element and transducer. Therefore, the quest of finding suitable interfacial element remains challenging for achieving handheld portability and miniaturization. The inculcation of nanomaterials for the designing of biosensors has greatly enhanced the performance and sensitivity of the existing biosensors as well as also opens the path for imbibing various novel signal transducers. The objective of nano-sensing platforms to detect a lower concentration of target analyte within the complex architecture of living systems [17] represented realistic picture of sensing devices.

\section{Samples}

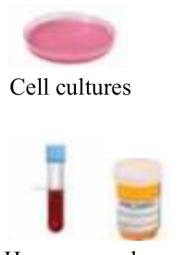

Human samples :

Blood ,Urine,Body fluids

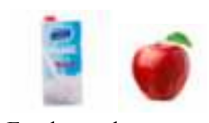

Food samples

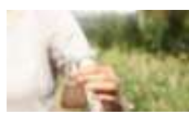

Environmental samples: Air,water,soil samples

\section{Analytes Bioreceptor Transducer}

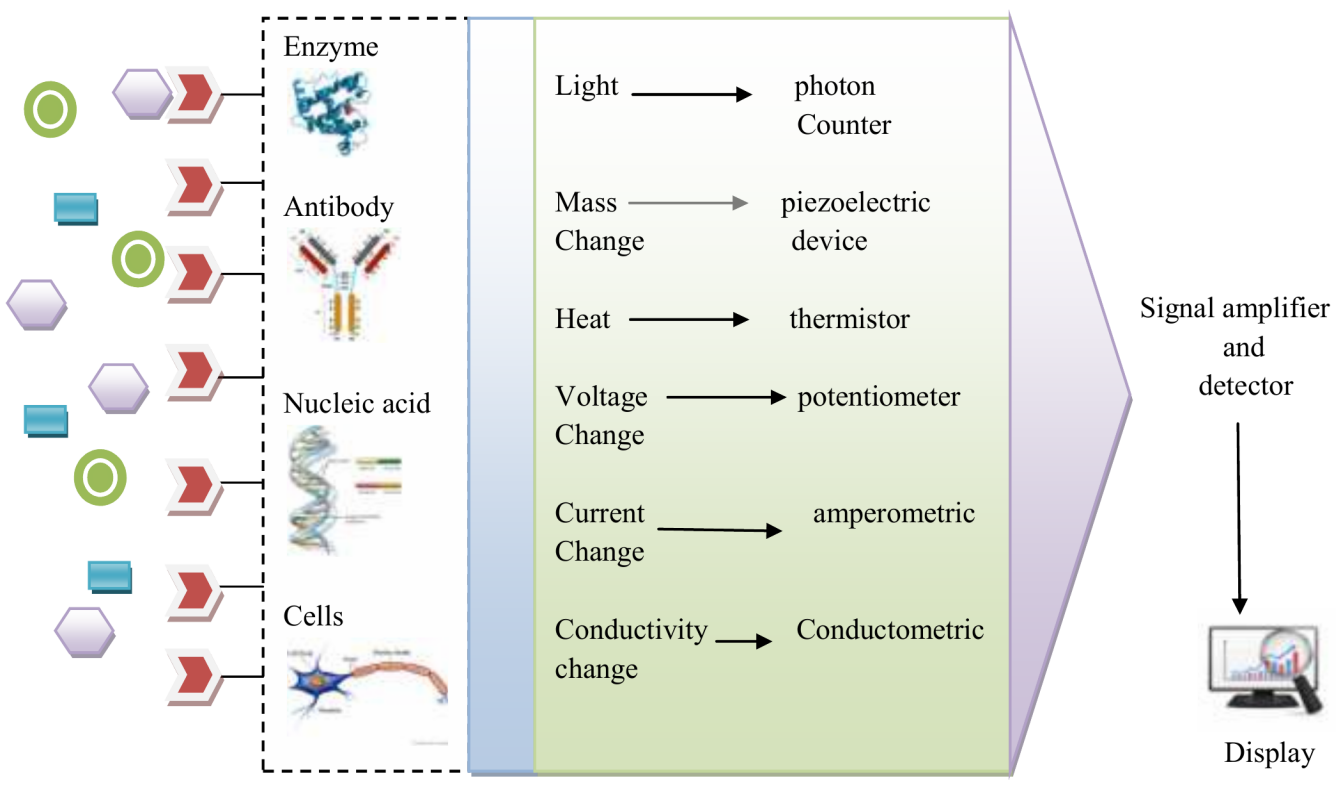

Figure 1. Basic components of biosensor including diverse samples, bio-receptors, transducers. 


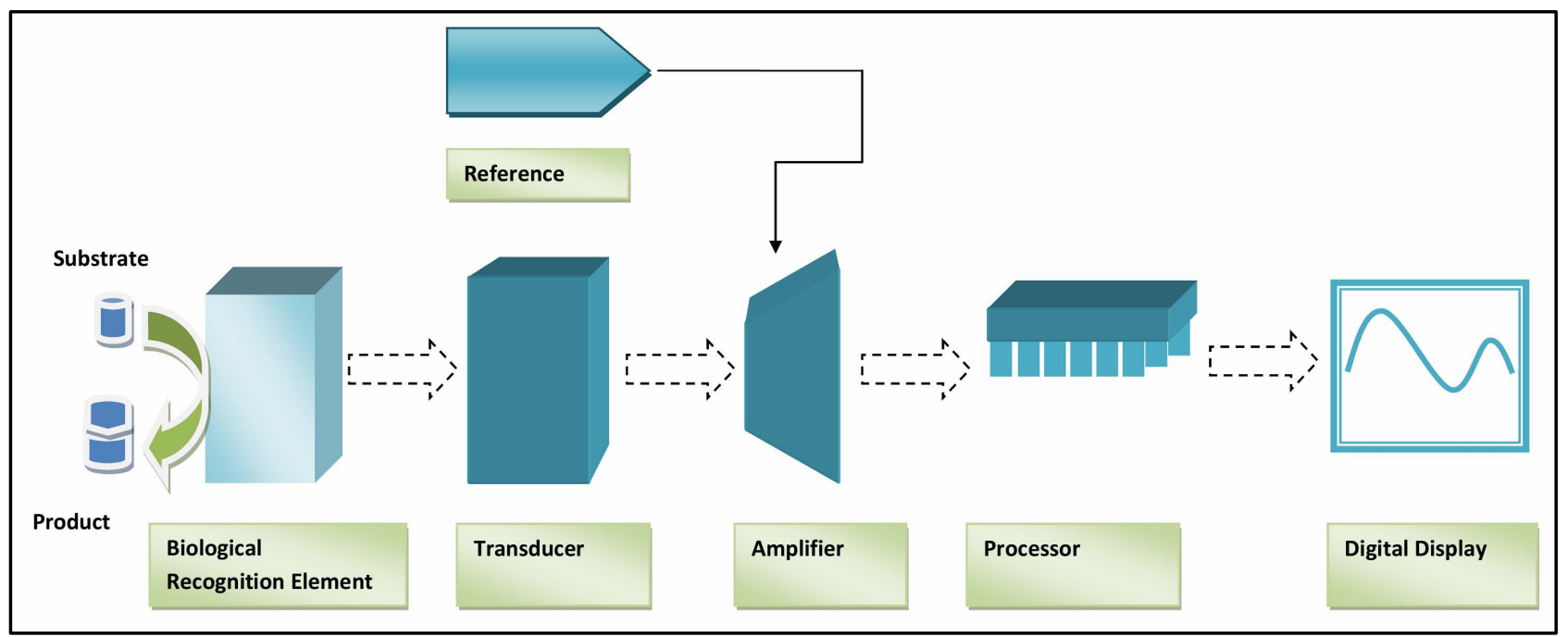

Figure 2. Principle of working of biosensor.

Currently various nano-architectures like nanowires, carbon nanotubes [18], magnetic nanoparticles [19], gold nanoparticles [20] and quantum dots [21] have been utilized for fabrication of biosensors.

\section{Importance of S-Layer Proteins in Bio-Sensors Development}

As described above, the challenging part of fabrication of biosensors is to develop interfacial platform or architecture for providing adequate interaction of bio-receptors with target biological molecules [22]. Apart from the above fact, the interfacial architecture has to act as immobilization matrix with a relevant binding to both biological entities as well as inorganic support and provide a well-defined spatial orientation, space and desired stability to the biological molecules. The stability and performance of biosensor has been perturbed by the aggregation or denaturation of biomolecules on the variety of surfaces and inorganic solid supports, electrodes then followed by loss of functionality. Therefore, extensive efforts have been made for the development of interfacial or intermediate layer between the bio-sensing moiety and various sensing surfaces. Various polymeric materials including agarose, polyethylene glycol, chitosan, hydrogel [23] [24] or self-assembled monolayers made up of silanes, alkanethiol, phosphonates, dialkylsulfides have been used for development of interfacial platforms [25] [26] [27] [28].

Currently, the emphasis is being laid on the utilization of surface layer proteins that has capability to self-assemble into mono or bilayer on the various sensing surfaces and interfaces as well as on nanomaterials. It serves as an excellent interfacial architecture that has been implied for the close association of bio-receptor with transducing surface leading to the amplified signals as compared to their other counterparts. Besides that, these proteins have been explicitly utilized as an intermediate layer for the development and fabrication of 
supported lipid membranes that mediates the suitable environment for understanding the reconstitution process of membrane-active peptides and integral, functional membrane proteins.

The inherent capabilities of tolerating the insertions of heterologous proteins and their functional groups without affecting the self-assembling process in geometrical order paved the way for scientific community to modify the lattice structure in a desired manner. The genetic engineering approaches opened up the glorious way for modifying the natural properties to create bioinspired and biomimetic materials with desired functional attributes. Currently, two common approaches have been used for the construction of fusion proteins 1) homologous expression and secretion by the producing cells 2) production and expression of surface layer proteins in a suitable host like E. coli [29]. The genetically engineered proteins open the avenue for exploring these proteins in sensing applications. The current literature provides immersive application of surface layer as bio-sensing component in the form of S-layer ultrafiltration membranes (SUM). These membranes are prepared by the deposition of S-layer components in microfiltration membranes, silicon chips and electrodes. Figure 3 describes the role of surface layer proteins as interfacial architecture for the development of biosensors [30]. These membranes provide stability to the bio-sensing element and can also be utilized in the development of supported lipid bilayers for biomimetic applications [31] [32] [33] [34]. Till date, various transducing platforms have been utilized for fabrication of bio-sensing platform based on surface layer proteins for detection and quantification of biomolecules. These are electrochemical, optical, piezoelectric, microfluidic based lab-on-a-chip, molecular imprinting-based biosensors. The sensitivity, selectivity and stability of bio-sensing element have been significantly enhanced by incorporation of surface layer proteins. The various examples have been summarized in the following section.

\section{Development of Biosensors Based on Surface Layer Proteins}

\subsection{Biosensors Based on Native S-Layer Proteins}

The path breaking discovery of glucose biosensor developed by Clark in 1962 paved the way for further developments in the bio-sensing field. In this, an electrochemical sensor was proposed by incorporating glucose oxidase as bio-recognition element [35]. An amperometric electrode has been constructed with permeable membrane in that the change in potential has been measured by the reaction of glucose with glucose oxidase enzyme. Till then this seminal development leads to the rigorous efforts for improvement in sensitivity of glucose biosensor and S-layer protein mediated bio-sensing overcomes the major limitations. As described in previous paragraph, for accomplishing the bio-sensing aspect, S-layer ultrafiltration membranes (SUMs) has been used as suitable matrix for immobilization of various enzymes, antibodies and ligands. The immobilization of enzymes has been mediated by covalent binding of carboxyl groups 


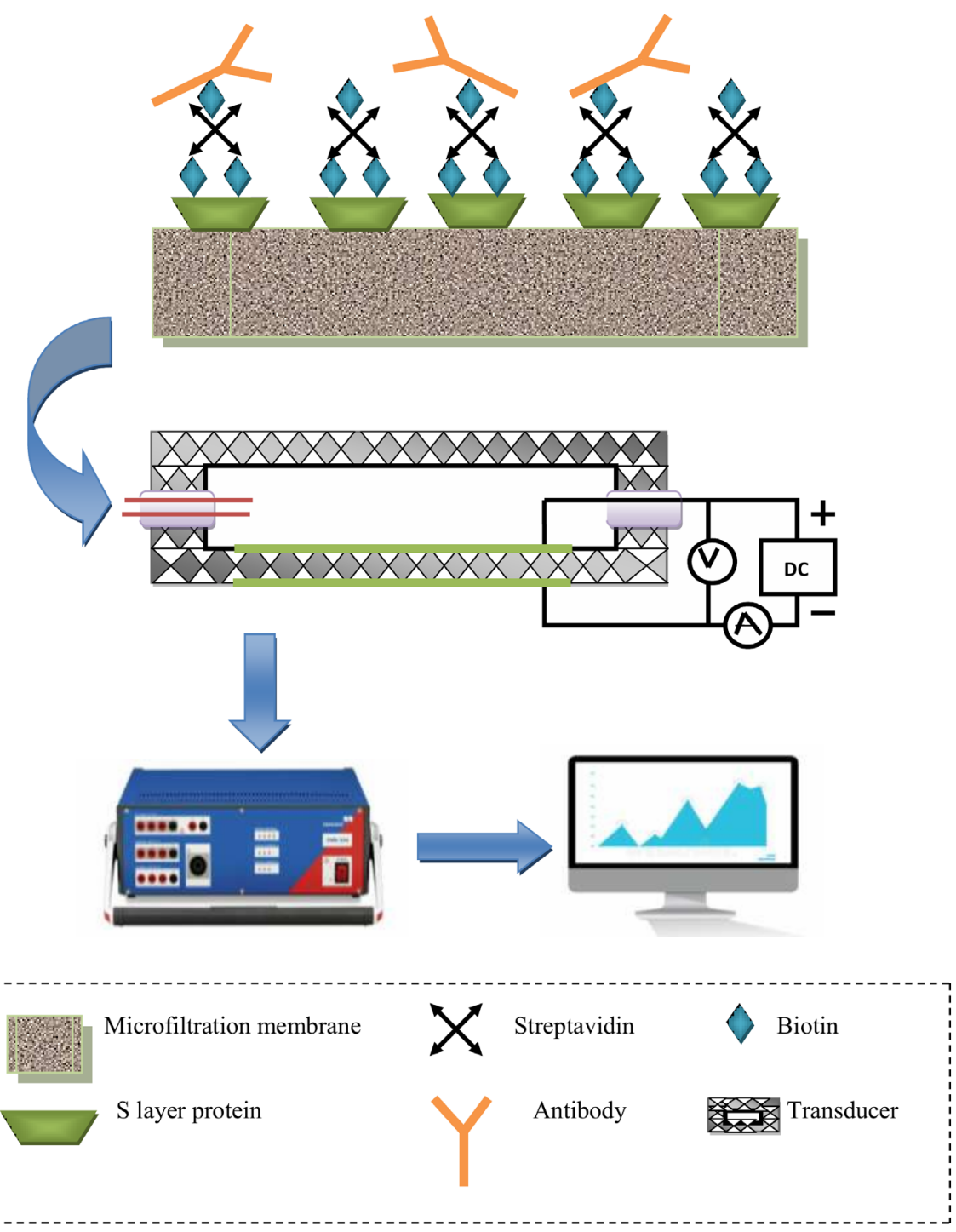

Figure 3. Importance of surface layer proteins as an interfacial architecture for the development of Bio-sensing platform [30].

of S-layer protein that was activated with carbodiimide followed by binding with amino groups present in the enzyme. The selective advantage conferred by S-layer has been acknowledged as 1) S-layers are formed with repetitive identical protein subunits 2) the directed and precise orientation of functional groups on the crystalline S-layer opened the avenue for geometrical well defined binding of enzyme monolayers.

Sleytr et al., [36] developed an amperometric biosensor employing glucose oxidase (GOD) as bio-recognition element that covalently bonded with SUM. The enzyme coated SUMs were layered with gold to function as working electrode. The developed electrode retained $40 \%$ of enzyme activity and shown high sensitivity (up to $12 \mathrm{mM}$ glucose), high signal amplification approximately 150 $\mathrm{nA} / \mathrm{mm}^{2} / \mathrm{mmol}$ glucose and fast response time up to $30 \mathrm{~s}$. The developed sensors showed stable response time up to $48 \mathrm{hrs}$ and shelf life up to 6 months. Moreo- 
ver, in the same line an amperometric biosensors based on multi-enzymes for quantification of sucrose by oxidation of hydrogen peroxide has been reported. The three enzymes namely GOD, invertase and mutarotase were immobilized on surface layer proteins with aspartic acid as spacer molecules. The S-layer protein was isolated from Clostridium thermohydrosulfuricum L111-69. The SUMs were prepared and loaded with respective enzymes followed by sputtering of gold to function as working electrode. The sensor displayed higher sensitivity up to $30 \mathrm{mM}$ sucrose with response time of $5 \mathrm{~min}$. and signal amplification up to 1 $\mu \mathrm{A} \mathrm{cm}{ }^{-2} \cdot \mathrm{mmol}^{-1}$ of sucrose. Furthermore, a fibre-optic biosensor was developed by immobilizing the glucose oxidase enzyme covalently on SUMs. The response was analyzed by measuring the fluorescence from oxygen optode comprising a ruthenium (II) complex as transducing element and sensor characteristics displayed promising credentials that had been compared with other optodes [37]. The developed biosensor opened a route for the development of micro-integrated optical biosensors.

However, the developed optical biosensor displayed considerable sensor merits but lagged with alteration in the enzyme structure therefore, considerable efforts have been done for alleviating this problem by providing application of platinum films by argon sputtering on enzyme monolayers immobilized on S-layer proteins [38]. Furthermore, this methodology has substantial limitations and circumvented by pulse-laser-deposition (PLD) technique. The reaction and laser parameters were optimized before the deposition on films contacting enzyme/S-layer composites and 70\% - 80\% retention of enzyme activity has been observed [39]. In addition to that, more rigorous efforts have been done for accurate on-line monitoring of glucose due to the complexity in blood environment. The microfluidic lab-on-a-chip was fabricated utilizing S-layer protein SbpA from Lysinibacillus sphaericus CCM 2177 [40]. The four micro-reactors containing (GOD) immobilized with S-layer protein operated in a feedback loop mechanism for specific and independent measurement of glucose. The beneficial aspects of utilizing surface layer protein have been visualized in-terms of elimination of adsorption process in the presence of fresh blood samples, plasma and human serum albumin. The sensitivity range of this device has been reported up to $0.5 \mathrm{mM}$ to $50 \mathrm{mM}$. This sensing device enables precise and drift-free measurement of glucose up to $2 \mathrm{hrs}$ at $37^{\circ} \mathrm{C}$ and implies successfully for multiplex analysis of complex samples.

Apart from glucose oxidase, the quantification of cholesterol has been performed by S-layer based bio-sensing approach by utilizing cholesterol oxidase as bio-recognition element. Initially stable monolayers of cholesterol oxidase have been formed at air-water interface using Langmuir technique, but after coating with S-layer proteins isolated from Bacillus sphaericus, more stable layers were observed [41]. The enhanced stability has been confirmed by surface pressure-molecular area $(\pi-A)$ isothermal technique and showed an ideal behavior. Furthermore, the developed mixed films (comprising cholesterol oxidase and 
S-layer proteins) were transferred using Langmuir-Blodgett technique on screen-printed carbon electrodes [42]. The characterization through AFM revealed the reduction in roughness of the surface of electrodes while CV studies confirmed the enhanced oxidation peak intensity due to the presence of S-layer proteins. Therefore, the detection limit and stability of the developed biosensors was enhanced by incorporating S-layer proteins. Moreover, the fiber optic sensor for the measurement of oxygen has been reported by Scheicher et al. [43]. The fabrication of sensor was accomplished by covalent binding of oxygen sensitive $\mathrm{Pt}(\mathrm{II})$ porphyry in dye with S-layer proteins. The signal was generated by cost effective optoelectronic parts like silicone photodiodes and light emitting diodes (LEDs) and the concentration of oxygen was measured by phase modulation fluorimetry. The quenching efficiency in terms of luminescence for the developed sensors has been reported to be 1.5 - 1.9 (expressed as the ratio of signal in the presence of air and nitrogen) and displayed comparable response with other sensing systems utilizing luminophores.

More recently, S-layer bio-sensing aspect has been utilized for molecular diagnostic for carcinoma cells. The developed biosensors worked on the principle of recognition of folate receptors that are highly expressed in cancerous cells [44]. The developed biosensor consists of gold surface that is immobilized with crystallized S-layer protein and functionalized with folate. The two transducing devices, quartz crystal microbalance and electrochemical biosensors have been utilized to distinguish between MCF-7 and human liver hepatocellular carcinoma (HepG2) cells as latter cells do not bind with folate. The quartz crystal microbalance dissipation monitoring (QCM-D) was utilized to distinguish between MCF-7 and HepG2 cells with real time monitoring under controlled conditions and displayed detection limit of $\left(1 \times 10^{5}\right.$ cells $\left./ \mathrm{mL}\right)$. The selectivity and the specificity of the developed biosensor were further confirmed by electrochemical measurements and the results were in agreement with the QCM-D sensor. Therefore, developing S-layer based bio-sensing mediates early diagnosis that can reduce the mortality rate due to cancer.

Moreover, an aptamer based bio-sensing approach utilizing S-layer proteins has been reported by Weinert et al. [45]. S-layer proteins isolated from L. sphaericus $J G$ - $A 12$ and $L$. sphaericus $J G$-B53 were bonded with thrombin-binding aptamer and an ofloxacin-binding aptamer that was mediated by different chemical cross-linkers. The drastic differences' were observed by high-through put analytical methodologies like resonant mirror sensing, Laser-induced fluorescence spectroscopy and QCM-D. There were no crystallization and thrombin binding were seen with monomers of S-layer protein after aptamer modification while aptamers linked with intact S-layer in surface or suspension were bonded with thrombin and ofloxcin. Therefore, the studies were well correlated and confirmed that, S-layer proteins represented as an interesting immobilization support for bio-molecular recognition.

The above said examples are giving highlights on biomedical applications of 
native S-layer proteins as bio-sensing matrix. Apart from these applications, the electrochemical biosensor was reported for the detection of uranyl $\left(\mathrm{UO}_{2}^{2+}\right)$ ions at picomolar concentration utilizing S-layer protein of Lysinibacillussphaericus $J G-A 12$ tethered on gold electrodes [46]. The developed sensor was compared with self-assembled monolayer based bio-sensing devices and displayed more stability, higher shelf-life and high selectivity over other cations including $\mathrm{Cd}^{2+}$, $\mathrm{Ni}^{2}, \mathrm{CO}^{2+}$ and $\mathrm{Cs}^{+}$. The studies have also given insight about the functionality of carboxyl and phosphate groups present in S-layer proteins for the involvement in $\left(\mathrm{UO}_{2}^{2+}\right)$ binding as chemical modification in S-layer proteins leads to prevented binding with $\mathrm{UO}_{2}^{2+}$ ions [47]. Therefore, the studies provided the basis for the utilization of S-layer protein as bio-sensing component for the development of biosensor for detection of other metal ions in heavy metal polluted sites.

\subsection{Genetically Engineered S-Layer Proteins Based Biosensors}

Recently the advent of genetic engineering approaches for the production of recombinant proteins metamorphosize the research development on surface layer proteins. The successful production of recombinant surface layer proteins provides incentive in terms of precise topographical features and tolerating the insertions of foreign proteins and their functional groups without affecting the self-assembling process in geometrical order. Till date, the most common surface layer protein core-streptavid in either at the $\mathrm{N}$-terminal or C-terminal end have been constructed [48] [49] and their biotechnological applications has been envisaged in the field of label-free sensing technology [50] manufacturing of protein/DNA chips and antigen carriers for vaccine delivery. The utilization of bio-sensing aspect of recombinant surface layer proteins has been reported by Nicolla et al. [29]. The streptavidin fusion S-layer protein SbpA isolated from Bacillus sphaericus CCM 2177 were recrystallized on gold surface or on gold chips precoated with thiolated secondary cell wall polymer (SCWP). After the recrystallization monolayers were formed followed with binding of biotinylated oligonucleotides. The hybridization experiments with fluorescently labeled probes were performed and assessed with surface-plasmon-field-enhanced fluorescence spectroscopy. The significant enhancement in the detection limit (1.57 $\mathrm{pM}$ ) was found after recrystallization of recombinant S-layer protein on SCWP-coated gold surface as compared with recrystallization of fusion proteins on plain gold surface $(8.2 \mathrm{pM})$. The further modification in chimeric S-layer systems was done with the same set up and label free detection was performed to detect prostate-specific antigen (PSA) [51] [52]. The sensing interface was composed of fusion S-layer protein expressing the antibody lattice of camel (variable domain of a heavy chain) against PSA and detected by SPR biochips.

Furthermore, this fusion S-layer protein was further crystallized on silica microbeads that served as an excellent biocompatible platform for microsphere-oriented detoxification system. The applicability of the developed system has been successfully visualized on the patients suffering from autoimmune dis- 
ease in which the S-layer sensing platform has been used for the extracorporeal blood purification [53]. The further efforts were done by incorporating Fc-binding Z-domain with S-layer protein to form fusion protein in the form of rSbpA/ZZ. The incorporated ZZ domains were synthetic analogue of the IgG-binding domain of pathogenic protein A from Staphylococcus aureus. The recombinant protein were recrystallized on cellulose based microbeads and the binding efficiency of these coated beads were found to be 20 times higher when it was compared with conventional immunosorbents utilized for extracting antibodies from the patients suffering from an autoimmune diseases [54].

In addition to that, the S-layer based bio-sensing platform has been successfully implied for the molecular diagnostics. The work has been accomplished with fusion of S-layer proteins (SbpA isolated from Bacillus sphaericus CCM 2177 and SbsB extracted from Geobacillusstearothermophilus PV72/p2) with peptide mimotopes F1 that mimics the epitope of Epstein-Barr virus (EBV) and overexpressed in Escherichia coli [55] [56]. The antibody binding capacity of both S-layer fusion protein were evaluated by an ELISA and immune-dot assays. The results confirmed that SbpA/F1 had a greater antibody affinity than SbsB/F1 in aqueous solution and in serum as well. The sensing platform displayed higher specificity (98.2\%) and sensitivity (89.3\%) with no cross-reactivity towards other related viral pathogenesis. More recently, an acoustic and (3D)-printed electrochemical biosensors were developed for the efficient defection of liver carcinoma cells through recognition of highly expressed tumor marker CD133 on the cell surface [57]. The S-layer fusion protein $\mathrm{rSbpA} / \mathrm{ZZ}$ protruding the ZZ-domain facilitated the immobilization of anti-CD133 antibodies as a sensing platform for detection of HepG2 cells. These sensors enabled real time detection through CV and QCM-D as transducing platform and represented themselves as cost effective and disposable technology for clinical applications.

\section{Current Progress}

The above discussion clearly revealed the fact that there is pressing need for identifying and developing well-organized interfacial structure for the development of biosensors. The explicit benefits of utilizing biological molecules having the capability of self-assembling on various surfaces and interfaces as well as tunable capacity for making ordered structures at nano-scale dimensions are of great significance in this field. Based on this context, surface layer proteins from different bacterial populations have been utilized as an immobilization matrix for binding various bio-molecules nanometer scale. In fact the progress in technology intervention and cross fertilization of different fields for generation of smart biosensors, there is no more clear demarcation between the transducers and bio-receptors has been visualized. There has been continuous search for surface layer proteins from archaea and GRAS organisms. More recently, three putative surface layer (S-layer) protein genes ( $s l p 1, s l p 2$, and $s l p 3$ ) has been identified from ViridibacillusarviJG-B58 strain that was isolated from heavy 
metal contaminated sites [58]. These proteins form double layer and showed $p 4$ symmetry that has been confirmed through Atomic Force Microscopy. The purified surface layer proteins were recrystallized on $\mathrm{SiO}_{2}$ substrates and significant self-assembling properties have been identified. The genomic analysis revealed that S-layer proteins of Viridibacillusarvi JG-B58 showed features of both Lactobacillus as well as of Bacillus-type S-layer proteins.

Currently, the innovative concept of making biomimetic functionalized lipid membranes constituting S-layer proteins that mimic the structure and functions of cell envelope structure of archaebacteria is being tested [59]. These biomimetic supra-molecular structures provide suitable platform for comprehensive understanding of membrane functionality as well as provide high mechanical stability, resistance towards high temperature, $\mathrm{pH}$ and osmotic stress. There is dearth of studies pertaining to the disintegration of surface layer proteins of archaea [60] and their reassembly into monomolecular layers therefore utilization of S-layer proteins from Gram-positive bacteria for the generation of functionalized lipid membrane has been reported till date. The possibility of chemical modification in the functional groups of native S-layer proteins or expression of desired functional groups in S-layer fusion proteins through genetic engineering approaches for the smooth and stable binding with various heads groups of lipids. In addition to that, an attractive feature of S-layer proteins comprises the recrystallization on lipid monolayer at the air-water interface or in the form of free standing layeras well as spherical liposome or emulsome [61]. Furthermore, the functional lipid membrane platforms can be generated on an already existing recrystallized S-layer proteins lattice. Therefore these studies lay strong foundation for the "proof of principle" for the suitable platform for development of bio-sensors.

More recently, the remarkable credentials manifested by surface layer proteins confer their suitability as excellent templates in the construction of molecularly imprinted polymer surfaces resulting the generation of imprints of controlled topographical features and surface functionality. Currently "bottom-up" approach utilizing surface layer proteins as template imprints for the formation of perfectly ordered arrays on variety of nanomaterials is exciting area of research. The ample research studies reported that metallic nanoparticles, quantum nanowires, carbon nanotubes act as marvelous platform for the S-layer based bio-molecular imprinting. The molecular imprinting of S-layer proteins has become valuable technology for the broad range of applications in clinical diagnostics, biosensors, food analysis, environmental analysis and vaccines development.

\section{Current Challenges and Future Prospects}

The thorough understanding of genetics, biochemistry and topological characteristics of surface layer proteins leads to the paradigmatic shift from basic science to translational applications and represented as an excellent example of biology-chemistry interface. Till date, the S-layer lattice of gram positive bacterium $G$. 
stearothermophilus $P V 72 / p 2$ have been utilized for the generation of stabilized lipid membranes as well as liposomes. The major challenge is associated with the compatibility, solubility, stability and viability of biological network with non-living system. The dynamic interactions among biological components as well as their scale up for their commercial utilization also pose great technological challenge. Apart from that, proteins as template molecule for molecular imprinting poses a great challenge due to the presence of charged amino acids and hydrophobic/hydrophilic regions accompanied with various surface functionalities. The aqueous solubility of proteins, restricted transfer of proteins in polymeric network, complexity in obtaining the highly purified proteins as template molecules, stability of proteins in imprinting process and removal of proteins from the polymeric network is quite difficult leading to the perturbations in adsorption and desorption processes. Furthermore, the outer surface of S-layer proteins in certain gram positive GRAS organisms are highly glycosylated therefore it is very skeptical that glycosylated proteins confer the same compatibility as reported in the current studies or not. In spite of these bottlenecks, the futuristic utility of S-layer proteins in the field of bio-sensing cannot be ruled out. The prospective areas of future developments can be envisaged in high-throughput screening of various drug molecules, DNA sequencing, development of electronic noses and tongues, lab-on-chip devices, disease diagnosis, liposomes and emulsomes for vaccines and drug delivery and various environmental bioremediation programmes.

\section{Conclusion}

The field of bio-sensing has accelerated the promising amalgamation of biological and engineering principles for the development of smart, portable, cost-effective, highly sensitive and selective bio-sensing devices. The desirable feature of the bio-sensing technology requires an interfacial surface that can enhance the efficiency of either pre-existing bio-sensors or novel inventions. The remarkable ability of native and genetically modified surface layer proteins self-assembling in defined orientation at various interfacial platforms led to their dramatic translational applications at nano-scale dimensions. The nano-biopatterning of S-layer may uncover an untraveled route for the successful prognosis, diagnosis and visualization of the therapeutic treatment for devastating disorders like cancer, neurodegenerative disorders, immune deficiencies, hereditary disorders and cardiovascular diseases. The significant progress has been envisaged for the construction of functional supra-molecular structures that paved the way for the development of more efficient biosensors. The proposed technology has just entered as a fresher in the field of biosensors. Further, in-depth knowledge is required for generation of more stable and compatible intelligent smart biosensors based on these proteins.

\section{Acknowledgements}

The authors are highly grateful to Gautam Buddha University for providing all 
necessary facilities and encouraging to write this manuscript. All authors declare that they have no conflict of interest.

\section{Conflicts of Interest}

The authors declare no conflicts of interest regarding the publication of this paper.

\section{References}

[1] Scognamiglio, V., Pezzotti, G., Pezzotti, I., Cano, J., Buonasera, K., Giannini, D. and Giardi, M.T. (2010) Biosensors for Effective Environmental and Agrifood Protection and Commercialization: From Research to Market. Microchimica Acta, 170, 215-225. https://doi.org/10.1007/s00604-010-0313-5

[2] Arora, P., Sindhu, A., Dilbaghi, N. and Chaudhury, A. (2011) Biosensors as Innovative Tools for the Detection of Food Borne Pathogens. Biosensors and Bioelectronics, 28, 1-12. https://doi.org/10.1016/j.bios.2011.06.002

[3] Ercole, C., Del, G.M., Mosiello, L., Baccella, S. and Lepidi, A. (2003) Escherichia coli Detection in Vegetable Food by a Potentiometric Biosensor. Sensors and Actuators B: Chemical, 91, 163-168. https://doi.org/10.1016/S0925-4005(03)00083-2

[4] Woolston, B.M., Edgar, S. and Stephanopoulos, G. (2013) Metabolic Engineering: Past and Future. Annual Review of Chemical and Biomolecular Engineering. 4, 259-288. https://doi.org/10.1146/annurev-chembioeng-061312-103312

[5] Haes, A.J. and Van Duyne, R.P. (2002) A Nanoscale Optical Biosensor: Sensitivity and Selectivity of an Approach Based on the Localized Surface Plasmon Resonance Spectroscopy of Triangular Silver Nanoparticles. Journal of the American Chemical Society, 124, 10596-10604. https://doi.org/10.1021/ja020393x

[6] Sára, M. and Sleytr, U.B. (2000) S-Layer Proteins. Journal of Bacteriology, 182, 859-868. https://doi.org/10.1128/JB.182.4.859-868.2000

[7] Engelhardt, H. and Peters, J. (1998) Structural Research on Surface layers: A Focus on Stability, Surface Layer Homology Domains, and Surface Layer-Cell Wall Interactions. Journal of Structural Biology, 124, 276-302.

https://doi.org/10.1006/jsbi.1998.4070

[8] Györvary, E.S., Stein, O., Pum, D. and Sleytr, U.B. (2003) Self-Assembly and Recrystallization of Bacterial S-Layer Proteins at Silicon Supports Imaged in Real Time by Atomic Force Microscopy. Journal of Microscopy, 212, 300-306. https://doi.org/10.1111/j.1365-2818.2003.01270.x

[9] Schuster, B. and Sleytr, U.B. (2000) S-Layer-Supported Lipid Membranes. Reviews in Molecular Biotechnology, 74, 233-254. https://doi.org/10.1016/S1389-0352(00)00014-3

[10] Schuster, B. and Sleytr, U.B. (2009) Composite S-Layer Lipid Structures. Journal of Structural Biology, 168, 207-216 https://doi.org/10.1016/j.jsb.2009.03.004

[11] Küpcü, S., Sára, M. and Sleytr, U.B. (1995) Liposomes Coated with Crystalline Bacterial Cell Surface Protein (S-Layer) as Immobilization Structures for Macromolecules. Biochimica et Biophysica Acta (BBA) -Biomembranes, 1235, 263-269. https://doi.org/10.1016/0005-2736(95)80013-6

[12] Mader, C., Küpcü, S., Sára, M. and Sleytr, U.B. (1999) Stabilizing Effect of an S-Layer on Liposomes towards Thermal or Mechanical Stress. Biochimica et Biophysica Acta (BBA) -Biomembranes, 1418, 106-116. https://doi.org/10.1016/S0005-2736(99)00030-9 
[13] Ucisik, M.H., Küpcü, S., Debreczeny, M., Schuster, B. and Sleytr, U.B. (2013) S-Layer Coated Emulsomes as Potential Nanocarriers. Small, 9, 2895-2904. https://doi.org/10.1002/smll.201203116

[14] Ucisik, M.H., Sleytr, U.B. and Schuster, B. (2015) Emulsomes Meet S-Layer Proteins: An Emerging Targeted Drug Delivery System. Current Pharmaceutical Biotechnology, 16, 392-405. https://doi.org/10.2174/138920101604150218112656

[15] Brown, S., Santa, M.J., John, P. and Walker, S. (2013) Wall Teichoic Acids of Gram-Positive Bacteria. Annual Review of Microbiology, 67, 313-336. https://doi.org/10.1146/annurev-micro-092412-155620

[16] Grieshaber, D., MacKenzie, R., Voeroes, J. and Reimhult, E. (2008) Electrochemical Biosensors-Sensor Principles and Architectures. Sensors, 8, 1400-1458. https://doi.org/10.3390/s80314000

[17] Zhang, X., Guo, Q. and Cui, D. (2009) Recent Advances in Nanotechnology Applied to Biosensors. Sensors, 9, 1033-1053. https://doi.org/10.3390/s90201033

[18] Cui, D., Tian, F., Coyer, S.R., Wang, J., Pan, B., Gao, F., He, R. and Zhang, Y. (2007) Effects of Antisense-Myconjugated Single-Walled Carbon Nanotubes on HL-60 Cells. Journal of Nanoscience and Nanotechnology, 7, 1639-1646. https://doi.org/10.1166/jnn.2007.348

[19] Pan, B., Cui, D., Sheng, Y., Ozkan, C., Gao, F., He, R. and Huang, T. (2007) Dendrimer-Modified Magnetic Nanoparticles Enhance Efficiency of Gene Delivery System. Cancer Research, 67, 8156-8163. https://doi.org/10.1158/0008-5472.CAN-06-4762

[20] Pan, B., Cui, D., Xu, P., Li, Q., Huang, T., He, R. and Gao, F. (2007) Study on Interaction between Gold Nanorod and Bovine Serum Albumin. Colloids and Surfaces A: Physicochemical and Engineering Aspects, 295, 217-222. https://doi.org/10.1016/j.colsurfa.2006.09.002

[21] You, X., He, R., Gao, F., Shao, J., Pan, B. and Cui, D. (2007) Hydrophilic High-Luminescent Magnetic Nanocomposites. Nanotechnology, 18, Article ID: 035701.

[22] Schmidt, J.J. and Montemagno, C.D. (2004) Bionanomechanical Systems. Annual Reviews of Materials Research, 34, 315-337. https://doi.org/10.1146/annurev.matsci.34.040203.115827

[23] Sackmann, E. (1996) Supported Membranes: Scientific and Practical Applications. Science, 271, 43-48. https://doi.org/10.1126/science.271.5245.43

[24] Rädler, J. and Sackmann, E. (1997) Functionalization of Solids by Ultrathin Soft Polymer Films and Polymer/Lipid Film Composites: Modeling of Cell Surfaces and Cell Recognition Processes. Current Opinion in Solid State and Materials Science, 2, 330-336. https://doi.org/10.1016/S1359-0286(97)80124-6

[25] Sleytr, U.B., Bayley, H., Sara,M., Breitwieser, A., Küpcü, S., Mader, C., Weigert S., Unger, F.M., Messner, P., Jahn-Schmid, B., et al. (1997) Applications of S-Layers. FEMS Microbiology Reviews, 20, 151-175. https://doi.org/10.1111/j.1574-6976.1997.tb00306.x

[26] Messner, P., Schäffer, C., Egelseer, E.M. and Sleytr, U.B. (2010) Prokaryotic Cell Wall Compounds: Structure and Biochemistry. In: Prokaryotic Cell Wall Components: Structure and Biochemistry Nanobiotechnological Applications of Slayers, Springer, Berlin/Heidelberg, 53-109.

[27] Sleytr, U.B., Egelseer, E.M., Ilk, N., Pum, D. and Schuster, B. (2007) S-Layers as a Basic Building Block in a Molecular Construction Kit. The FEBS Journal, 274, 323-334. https://doi.org/10.1111/j.1742-4658.2006.05606.x 
[28] Sleytr, U.B., Schuster, B., Egelseer, E.M., Pum, D., Horejs, C.M., Tscheliessnig, R. and Ilk, N. (2011) Nanobiotechnology with S-Layer Proteins as Building Blocks. Progress in Molecular Biology and Translational Science, 103, 277-352. https://doi.org/10.1016/B978-0-12-415906-8.00003-0

[29] Ilk, N. Egelseer, E.M. and Sleytr, U.B. (2011) S-Layer Fusion Proteins-Construction Principles and Applications. Current Opinion in Biotechnology, 22, 824-831. https://doi.org/10.1016/j.copbio.2011.05.510

[30] Schuster, B. (2018) S-Layer Protein-Based Biosensors. Biosensors, 8, 40. https://doi.org/10.3390/bios8020040

[31] Liew, P.W.Y., Jong, B.C. and Najimudin, N. (2015) Hypothetical Protein Avin_16040 as the S-Layer Protein of Azotobacter vinelandii and Its Involvement in Plant Root Surface Attachment. Applied and Environmental Microbiology, 81, 7484-7495. https://doi.org/10.1128/AEM.02081-15

[32] Schuster, B. (2005) Biomimetic Design of Nanopatterned Membranes. NanoBiotechnology, 1, 153-164. https://doi.org/10.1385/NBT:1:2:153

[33] Schuster, B., Kepplinger, C. and Sleytr, U.B. (2010) Biomimetic S-Layer Stabilized Lipid Membranes. In: Toca-Herrera, J.L., Ed., Biomimetics in Biophysics. Model Systems, Experimental Techniques and Computation, Research Signpost, Kerala, $1-12$.

[34] Schuster, B., Pum, D. and Sleytr, U.B. (2008) S-Layer Stabilized Lipid Membranes. Biointerphases, 3, 3-11. https://doi.org/10.1116/1.2889067

[35] Clark Jr., L.C. and Lyons, C. (1962) Electrode Systems for Continuous Monitoring in Cardiovascular Surgery. Annals of the New York Academy of Sciences, 102, 29-45. https://doi.org/10.1111/j.1749-6632.1962.tb13623.x

[36] Neubauer, A., Pum, D. and Sleytr, U.B. (1993) An Amperometric Glucose Sensor Based on Isoporous Crystalline Protein Membranes as Immobilization Matrix. Analytical Letters, 26, 1347-1360. https://doi.org/10.1080/00032719308017417

[37] Neubauer, A., Pum, D. and Sleytr, U.B. (1996) Fibre-Optic Glucose Biosensor Using Enzyme Membranes with 2-D Crystalline Structure. Biosensors and Bioelectronics, 11, 317-325. https://doi.org/10.1016/0956-5663(96)88418-1

[38] Neubauer, A., Pentzien, S., Reetz, S., Kautek, W., Pum, D. and Sleytr, U.B. (1997) Pulsed-Laser Metal Contacting of Biosensors on the Basis of Crystalline Enzyme-Protein Layer Composites. Sensors and Actuators B: Chemical, 40, 231-236. https://doi.org/10.1016/S0925-4005(97)80267-5

[39] Pum, D., Neubauer, A., Sleytr, U.B., Pentzien, S., Reetz, S. and Kautek, W. (1997) Physico-Chemical Properties of Crystalline Nanoscale Enzyme-Protein-Metal Layer Composites in Biosensors. Berichte der Bunsengesellschaft für physikalische Chemie, 101, 1686-1689. https://doi.org/10.1002/bbpc.19971011127

[40] Picher, M.M., Küpcü, S., Huang, C.J., Dostalek, J., Pum, D., Sleytr, U.B. and Ertl, P. (2013) Nanobiotechnology Advanced Antifouling Surfaces for the Continuous Electrochemical Monitoring of Glucose in Whole Blood Using a Lab-on-a-Chip. Lab on a Chip, 13, 1780-1789. https://doi.org/10.1039/c3lc41308j

[41] Ferraz, H.C., Guimarães, J.A., Alves, T.L.M. and Constantino, C.J.L. (2011) Monomolecular Films of Cholesterol Oxidase and S-Layer Proteins. Applied Surface Science, 257, 6535-6539. https://doi.org/10.1016/j.apsusc.2011.01.143

[42] Guimarães, J.A., Ferraz, H.C. and Alves, T.L.M. (2014) Langmuir-Blodgett Films of Cholesterol Oxidase and Slayer Proteins onto Screen-Printed Electrodes. Applied Surface Science, 298, 68-74. https://doi.org/10.1016/j.apsusc.2014.01.108 
[43] Scheicher, S.R., Kainz, B., Köstler, S., Suppan, M., Bizzarri, A., Pum, D., Sleytr, U.B. and Ribitsch, V. (2009) Optical Oxygen Sensors Based on Pt(II) Porphyrin Dye Immobilized on S-Layer Protein Matrices. Biosensors and Bioelectronics. 25, 797-802. https://doi.org/10.1016/j.bios.2009.08.030

[44] Damiati, S., Peacock, M., Sleytr, U.B. and Schuster, B. (2018) Bioinspired Detection Sensor Based on Functional Nanostructures of S-Proteins to Target the Folate Receptors in Breast Cancer Cells. Sensors and Actuators B: Chemical, 267, 224-230. https://doi.org/10.1016/j.snb.2018.04.037

[45] Weinert, U., Vogel, M., Reinemann, C., Strehlitz, B., Pollmann, K. and Raff, J. (2015) S-Layer Proteins as an Immobilization Matrix for Aptamers on Different Sensor Surfaces. Engineering in Life Sciences, 15, 710-720. https://doi.org/10.1002/elsc.201400204

[46] Pollmann, K., Raff, J., Merroun, M., Fahmy, K. and Selenska-Pobell, S. (2006) Metal Binding by Bacteria from Uranium Mining Waste Piles and Its Technological Applications. Biotechnology Advances, 24, 58-68. https://doi.org/10.1016/j.biotechadv.2005.06.002

[47] Conroy, D.J.R., Millner, P.A., Stewart, D.I. and Pollmann, K. (2010) Biosensing for the Environment and Defence: Aqueous Uranyl Detection Using Bacterial Surface Layer Proteins. Sensors, 10, 4739-4755. https://doi.org/10.3390/s100504739

[48] Moll, D., Huber, C., Schlegel, B., Pum, D., Sleytr, U.B. and Sára, M. (2002) S-Layer-Streptavidin Fusion Proteins as Template for Nanopatterned Molecular Arrays. Proceedings of the National Academy of Sciences of the United States of America, 99, 14646-14651. https://doi.org/10.1073/pnas.232299399

[49] Huber, C., Liu, J., Egelseer, E.M., Moll, D., Knoll, W., Sleytr, U.B. and Sára, M. (2006) Heterotetramers Formed by an S-Layer-Streptavidin Fusion Protein and Core-Streptavidin as Nanoarrayed Template for Biochip Development. Small, 2, 142-150. https://doi.org/10.1002/smll.200500147

[50] De Yoreo, J.J., Chung, S. and Friddle, R.W. (2013) In Situ Atomic Force Microscopy as a Tool for Investigating Interactions and Assembly Dynamics in Biomolecular and Biomineral Systems. Advanced Functional Materials, 23, 2525-2538. https://doi.org/10.1002/adfm.201203424

[51] Pleschberger, M., Neubauer, A., Egelseer, E.M., Weigert, S., Lindner, B., Sleytr, U.B., Muyldermans, S. and Sára, M. (2003) Generation of a Functional Monomolecular Protein Lattice Consisting of an S-Layer Fusion Protein Comprising the Variable Domain of a Camel Heavy Chain Antibody. Bioconjugate Chemistry, 14, 440-448. https://doi.org/10.1021/bc025603+

[52] Pleschberger, M., Saerens, D., Weigert, S., Sleytr, U.B., Muyldermans, S., Sára, M. and Egelseer, E.M. (2004) An S-layer Heavy Chain Camel Antibody Fusion Protein for Generation of a Nanopatterned Sensing Layer to Detect the Prostate-Specific Antigen by Surface Plasmon Resonance Technology. Bioconjugate Chemistry, 15, 664-671. https://doi.org/10.1021/bc049964w

[53] Weber, V., Ilk, N., Völlenkle, C., Weigert, S., Sára, M., Sleytr, U.B. and Falkenhagen, D. (2002) Extrakorporale Blutreinigung mit spezifischen Absorbentien auf Basis der S-Schicht-Technologie. In: Dézsy, J., Ed., Medizin 2002-Aus Forschung und Praxis. Dr. Peter Müller Verlag, Wien, Austria.

[54] Völlenkle, C., Weigert, S., Ilk, N., Egelseer, E., Weber, V., Loth, F., Falkenhagen, D., Sleytr, U.B. and Sára, M. (2004) Construction of a Functional S-Layer Fusion Protein Comprising an Immunoglobulin G-Binding Domain for Development of Specific Adsorbents for Extracorporeal Blood Purification. Applied and Environmental 
Microbiolgy, 70, 1514-1521. https://doi.org/10.1128/AEM.70.3.1514-1521.2004

[55] Tschiggerl, H., Breitwieser, A., de Roo, G., Verwoerd, T., Schäffer, C. and Sleytr, U.B. (2008) Exploitation of the S-Layer Self-Assembly System for Site Directed Immobilization of Enzymes Demonstrated for an Extremophilic Laminarinase from Pyrococcus Furiosus. Journal of Biotechnology, 133, 403-411. https://doi.org/10.1016/j.jbiotec.2007.09.018

[56] Tschiggerl, H., Casey, J.L., Parisi, K., Foley, M. and Sleytr, U.B. (2008) Display of a Peptide Mimotope on a Crystalline Bacterial Cell Surface Layer (S-Layer) Lattice for Diagnosis of Epstein-Barr Virus Infection. Bioconjugate Chemistry, 19, 860-865. https://doi.org/10.1021/bc7003523

[57] Damiati, S., Küpcü, S., Peacock, M., Eilenberger, C., Zamzami, M., Qadri, I., Choudhry, H., Sleytr, U.B. and Schuster, B. (2017) Acoustic and Hybrid 3D-Printed Electrochemical Biosensors for the Real-Time Immunodetection of Liver Cancer Cells (HepG2). Biosensors and Bioelectronics, 94, 500-506.

https://doi.org/10.1016/j.bios.2017.03.045

[58] Matthias, S., et al. (2016) Characterization of Three Different Unusual S-Layer Proteins from Viridibacillus arvi JG-B58 that Exhibits Two Super-Imposed S-Layer Proteins. PLOS ONE, 11, e0156785.

[59] Sleytr, U.B., Messner, P., Pum, D. and Sára, M. (1999) Crystalline Bacterial Cell Surface Layers (S Layers): From Supramolecular Cell Structure to Biomimetics and Nanotechnology. Angewandte Chemie International Edition, 38, 1034-1054.

[60] König, H. (1988) Archaebacterial Cell Envelopes. Canadian Journal of Microbiology. 34, 395-406. https://doi.org/10.1139/m88-071

[61] Ucisik, M.H., Küpcü, S., Breitwieser, A., Gelbmann, N., Schuster, B. and Sleytr, U.B. (2015) S-Layer Fusion Protein as a Tool Functionalizing Emulsomes and CurcuEmulsomes for Antibody Binding and Targeting. Colloids and Surfaces B: Biointerfaces, 128, 132-139. https://doi.org/10.1016/j.colsurfb.2015.01.055

\section{Abbreviations}

CV: Cyclic Voltammetry

GOD: Glucose oxidase

GRAS: Generally regarded as safe

LEDs: Light Emitting Diodes

MCF-7: Michigan Cancer Foundation-7

PLD: Pulse laser deposition

QCM: Quartz Crystal Microbalance

SCWP: Secondary cell wall polymers

SLPs: Surface layer proteins

SUM: S-layer ultrafiltration membranes 